\title{
Left ventricular myxoma
}

\author{
Ali Kutsal', Murat Koç²
}

1) Dr.Sami Ulus Research and Training Hospital, Department of Cardiovascular Surgery, Prof. Dr., Ankara, Turkey

2) Dr.Sami Ulus Research and Training Hospital, Department of Cardiovascular Surgery, Op. Dr., Ankara, Turkey

\begin{abstract}
A 31 year-old woman complaining of mild dyspnea and fatique was admitted to our clinic.A two-dimensional echocardiogram revealed a $2 \times 2 \mathrm{~cm}$ mobile mass in the left ventricle. A $2 \times 3 \mathrm{~cm}$ mobile,pedinculated,gelatinous mass originating from the left ventricular lateral wall was removed by left ventriculotomy and histological features of the tumor indicated a myxoma.
\end{abstract}

Keywords: Left ventricular myxoma,left ventricular mass,cardiac surgery 


\section{Introduction}

Myxomas are round or oval tumors with a smooth or slightly lobulated surface.Most are polypoid,relatively compact,pedunculated,and mobile.Although intracardiac myxoma is the most common tumor of the heart with an estimated incidence of 0.5 per million population per year,only $3-4 \%$ of myxoma occur in the left ventricle ${ }^{1,2,3}$.

Myxoma has the potential of producing a triad of obstruction,embolisation and constitutional symptoms. The symptoms have varied greatly, depending on the size and the localization of the tumor. Systemic manifestations, which are noted in $90 \%$ of patients consist of weight loss, fever, anemia, elevated sedimentation rate and elevated immunglobulin concentration (usually $\mathrm{IgG}$ ). Surgery should be performed as soon as diagnosis is confirmed.

Left ventricular myxoma may be removed via the left atrium, left ventricle or transaortic approach. Tumor in the left ventricle outflow tract may be approached transaortically ${ }^{4}$, but this approach carries an increased risk for systemic embolization. ${ }^{5}$ Left-sided transatrial exposure alone may be difficult to achieve without risking any damage to the subvalvar apparatus of the mitral valve. Ventriculotomy is another approach with possible damage to small coronary artery branches. ${ }^{5}$

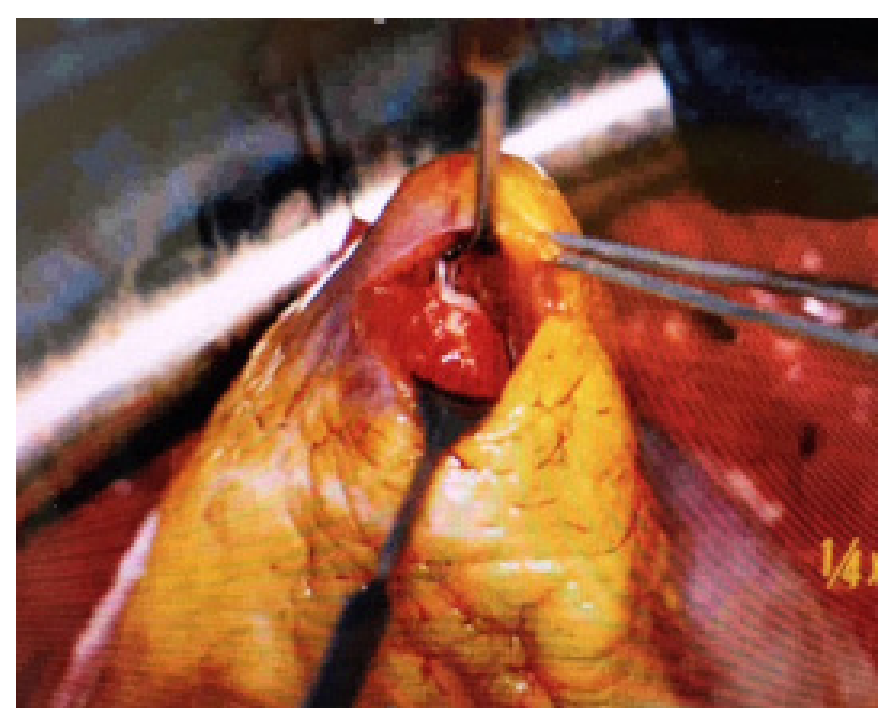

Figure 1: The appearence of the myxoma through the ventriculotomy.
Adequate surgical approach is important for preventing complications and recurrence.

\section{Case Report}

A 31 year-old woman complaining of mild dyspnea and fatique was admitted to our clinic. Physical examination were normal. A two-dimensional echocardiogram revealed a $2 \times 2 \mathrm{~cm}$ mobile mass in the left ventricle. In addition to the routine blood tests, immunglobulin concentrations, $\mathrm{C} 3 \mathrm{c}$ and $\mathrm{C} 4$ levels were measured. $\operatorname{IgG}(14.220 \mathrm{~g} / 1), \operatorname{IgM}(1.244 \mathrm{~g} / \mathrm{l}), \operatorname{IgA}(1.209 \mathrm{~g} / \mathrm{l})$ and $\mathrm{C} 4$ levels $(0.230 \mathrm{~g} / \mathrm{l})$ were normal. C3c level was higher than normal $(1.169 \mathrm{~g} / \mathrm{l})$.

With the diagnosis of left ventricular mobile mass (myxoma ?) she was operated. After performing median sternotomy and systemic heparinization cardiopulmonary bypass with bicaval and aortic cannulation was initiated. After systemic cooling to $300 \mathrm{C}$, aortic cross clamp was applied and the heart was arrested with antegrade cold crystalloid cardioplegia. A left atriotomy was performed and the mitral leaflets were gently retracted. However, it was very difficult to reach the mass without damaging the subvalvular apparatus of the mitral valve. Therefore left ventriculotomy was performed.

A $2 \times 3 \mathrm{~cm}$ mobile, pedinculated, gelatinous mass originating from the left ventricular lateral wall was re-

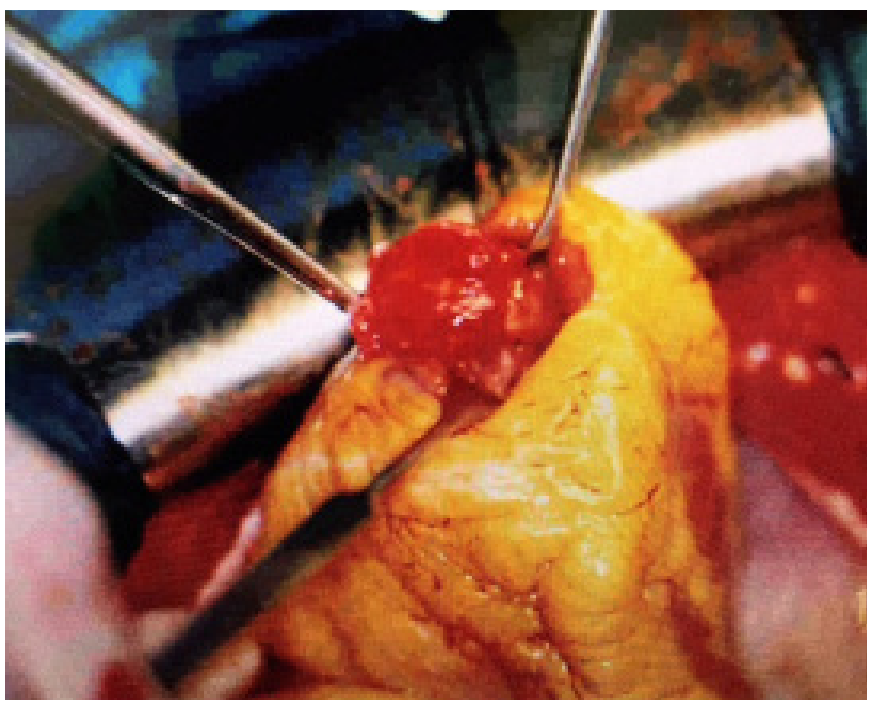

Figure 2: A $2 \times 3 \mathrm{~cm}$,pedinculated gelatinous mass was resected. 
moved. Then left ventriculotomy was closed with teflon strips. Histopathological examination confirmed the diagnosis of myxoma.

The postoperative course was uneventful, and the patient was discharged on the sixth postoperative day.

One year follow-up revealed no recurrence, and she was asymptomatic.

\section{Discussion}

Intracardiac myxoma is the most common benign tumor of the heart which occurs most commonly in women from 30 to 60 years of age. Children have a higher incidence of ventricular myxoma than do adults. ${ }^{6}$ Women are affected 3 times more often than are men and a short duration of symptoms is also characteristic. Emboli from left ventricular tumors may mimic multiple sclerozis. ${ }^{7}$ Accurate preoperative information about a myxoma in relation to its shape, size, mobility, texture, number of lesions and the clear localization is indispensable for determining the most appropriate operative procedure. ${ }^{8}$ Two dimensional echocardiogram or MRI are adequate diagnostic modalities for these information.

To minimize the risk of perioperative embolism, gentle handling of the heart during cannulation is important.Transaortic, transmitral or transvantricular approach may be employed for left ventricular myxomas. Transventricular approach should be avoided when ever possible in order not to impair the left ventricular function. The deepest localization of the myxoma in the left ventricle in our patient forces us to perform a ventriculotomy. We performed transmitral approach first, but as it was impossible to resect it without damaging the subvalvular tissue, we performed ventriculotomy. Both the myxoma and its pedicle were excised totally.

Following excision of the myxoma, the atrium and ventricle should be irrigated and aspirated carefully for any residual tumor fragments. ${ }^{9}$

It is concluded that excision of the cardiac myxoma is curative and radical tumor excision may prevent recurrence. The possible causes of recurrence are inadequate resection, tumor implantation during the operation, and multicentric growth. ${ }^{10}$ At present, it is generally believed that the multigrowth potential of the tumor seems more important than inadequate surgical resection in determining recurrence. Even if benign, a recurrent myxoma may be clinically more agressive than the primary tumor. The recommended approach during a secondary operation includes a thorough inspection of all cardiac chambers and complete excision of all growths, with a wider and deeper margin of underlying endocardium than usual. Regular follow up with serial two-dimensional echocardiograms is particularly important in this group, who are at a high risk for the development of additional metachronous cardiac lesions. Despite careful operation for recurrent myxoma, the risk of a second recurrence is high and has been estimated at $25 \%{ }^{10}$ 


\section{References}

1. Keeling IM,Oberwalder P,Anelli-Monti M,Schuchlenz H,Demel U,Tilz GP,Rehak P,Rigler B.Cardiac myxomas:24 years of experience in 49 patients.Eur J Cardiothorac Surg 2002;22:971-977.

2. Cooley DA.Surgical treatment of cardiac neoplasms:32-year experience.Thorac Cardiovasc Surg 1990;38(Suppl 2):176-182.

3. Reynen K.Cardiac myxomas.N Engl J Med 1995;333:1610-1617.

4. Natale E, Minardi G, Casali G, Pulignano G, Musumeci F. Left ventricular myxoma originating from the interventricular septum and obstructing the left ventricular outflow tract. Europ J Echocardiography $2008 ; 9: 84-85$.

5. Keeling I,Oberwalder P,Rigler B.Transaortic Access for excision of a left ventricular myxoma.Ann Thorac Surg 1999;68:2383-2391.
6. Reddy SN, Sunil G, Kumar RK. Surgical removal of a left ventricular myxoma in an infant. Ann Pediatr Cardiol. 2013 ;6(2):179-81

7. Kawano H,Tayama K,Akasu K.Left ventricular myxoma:Report of a case.Surg Today 2000;30:1112-1114.

8. Schröder C, Leukhardt WH, Hsiao EM, Farah MG, Markowitz AH. Transaortic video-assisted resection of a recurrent left ventricular myxoma. Ann Thorac Surg. 2013 ;95(1):340-2.

9. Abad C,Novoa J, Delgado A,Alonso A. Myxoma of the Left Ventricle. Tex Heart Inst J 2014;41(4):395-400.

10. Qin W, Wang L, Chen X, Liu P, Wang R. Left ventricular myxoma: a case report. J Biomed Res. 2014 ;28(6):506-8.

Received: 14/03/2015

Accepted: 19/07/2015

Published: 15/10/2015

Disclosure and conflicts of interest:

The authors declare no conflict of interest.

\section{Corresponding author:}

Prof. Dr. Ali Kutsal

Mail: akutsal@gmail.com 